ISSN $0717-5051$

http://revistaurbanismo.uchile.cl

\title{
Territorialidad, redes y debate urbanístico
}

Territoriality, networks and urban debate

María Isabel Pavez R.

\section{Resumen}

Pensamiento actual sobre un tipo de territorialidad marginada hasta ahora, a partir de la cual se enriquecería el concepto y la práctica del Urbanismo.

Palabras clave

Redística, planificación urbana, urbanismo de redes.

\section{Abstract}

Current thinking on a kind of territoriality marginalized until now, from which enriched the concept and practice of urban planning.

\section{Key words}

Urban planning, urban networks.

\section{Sumario}

La ciudad: un oscuro objeto del deseo

Urbanista de fin de siglo: un técnico, entre muchos

Críticas a la manera dominante de pensar la ciudad, y también las redes

El movimiento como esencia de la urbanidad

La accesibilidad a las redes: un objetivo cívico

Legitimidad del urbanismo en el campo de las redes

Organización territorial en red

Aproximación sistémica y función relacional de las redes

La naturaleza del desafío al Urbanismo 


\section{La ciudad: un oscuro objeto del deseo}

Parece oportuno preguntarse, si la orientación del urbanismo hacia la protección del medio ambiente, o del patrimonio, hacia la participación de los habitantes en las decisiones sobre su hábitat, o hacia la arquitectura y la monumentalidad, refiere a cuerpos teóricos y prácticos respondiendo a la envergadura y complejidad de los problemas de las metrópolis al fin del siglo XX.

Diversos diagnósticos indican que el problema fundamental es que el urbanismo, tanto en países desarrollados como en desarrollo, no está creando, o apropiándose de herramientas que le permitan pensar la ciudad tal como ella es realmente hoy, tal como proviene de evoluciones anteriores, tal como se va transformando en su marcha hacia el futuro ${ }^{1}$. Aun cuando las nuevas tecnologías del transporte y la comunicación han ido afectando la relación del hombre con el tiempo, el espacio y el prójimo, persiste la imagen de la ciudad tradicional y discreta, cuyo horizonte era el de la sociedad sedentaria ("pedestrian city") ${ }^{2}$. Allí cada uno se identificaba con su ambiente urbano y con su barrio, en los que se encontraba bien, y con un nivel de movilidad próximo a cero.

Choay observa dicha persistencia ligada a la de otra imagen e ilusión: la de la arquitectura eterna ${ }^{3}$. Bassand señala que ciertos medios intelectuales y profesionales analizan la realidad urbana contemporánea en términos de "ciudad" -como si vivieran en el siglo XIX o, aún, en el XV-, proponiendo políticas para su revitalización y el renacimiento de su "centro", cuando estos ya sólo existen "como mitos, trazos, o sedimentos", siendo arriesgado adoptar opciones de futuro "en función de organismos difuntos" ${ }^{4}$.

Mientras algunos piensan que la única salida posible del urbanismo del siglo XXI es que este sea rigurosamente arquitectónico ${ }^{5}$, Chalas denuncia la existencia de una especie de "complejo de Noé", en función del cual el arca de muchos urbanistas sólo está salvando del diluvio universal la "forma urbana", la que sería el molde de una nueva sociedad $^{6}$. Encontramos aquí la conjetura de Hopenhayn, en el sentido de que para algunos el goce actual por la vida, frente a un escenario discontinuo, incierto, fragmentado y cambiante, se encuentra en el "gusto por las formas"7.

1 DUPUY, Gabriel, L'Urbanisme des Réseaux: Théories et Méthodes, Armand Colin Editeur, Paris, 198 págs ilustradas, 1991, p.10.

2 TARR, Joël; DUPUY,Gabriel, Technology and de Rise of the Networked City in Europe and America,Philadelphie, Temple University Press, 1988, y TARR, J.; ROSE, M.; KONVITZ, J.W., "Technological Networks and the American City: Some Historiographical Notes", en: Flux, No1, printemps, 1990, citados por Dupuy, 1991, op.cit.

3 CHOAY, Françoise, "Le règne de l'urbain et la mort de la ville", en: La Ville, Art et Architecture en Europe 1870 -1993, Ed. C. Georges Pompidou, 467 págs., París, Febrero de 1994, pp. 26-35.

4 BASSAND, M., "La Région urbaine et la société programmée", en: Polyrama, N057,1983, citado por Dupuy, 1991, op. cit.

5 FIGUEROA s., Jonás, "Arquitectos y Urbanistas", en: El Mercurio, 29 de mayo de 1994, Santiago de Chile. 6 CHALAS, Y., "L'Imaginaire aménageur ou le complexe de Noé", en: Les Annales de la Recherche Urbaine, N042, 1989, citado por Dupuy, 1991, op.cit., p.61.

7 HOPENHAYN,Martín, Ni apocalípticos ni integrados. Aventuras de la modernidad en América Latina, Fondo de Cultura Económica, Santiago de Chile, 1994, 281 págs. El autor se pregunta si son propicios para motivar 
Desde las experiencias del Modernismo hasta hoy, tampoco la arquitectura urbana ha asumido el fenómeno metropolitano. I. de Solá-Morales, quien también estima que las enormes concentraciones urbanas ya no pueden ser pensadas como ciudades en el sentido convencional del término, sugiere titular una historia de la ciudad moderna hecha desde la arquitectura, "La ciudad como oscuro objeto del deseo": Para la economía, la ciudad existe como mercado; para la semiótica, como sistema de información; para la política, como ciudad, civitas, en la que se canalizan los valores colectivos de la convivencia. Hay también una ciudad vista como arquitectura, y la historia de la arquitectura urbana de los últimos cincuenta años, es también la historia de este deseo: hacer ciudad desde la arquitectura.

La cultura moderna, tan fragmentada y especializada hizo que cada uno de estos paradigmas fuera autónomo y absoluto ${ }^{8}$. En los países del Tercer Mundo la arquitectura de la ciudad moderna condujo a realizar experiencias totales: Chandigarh, de Le Corbusier; Brasilia, de Costa y Niemayer.

Solá-Morales piensa que la naturaleza de la ciudad-metrópoli impone un desafío que la arquitectura también debe encarar, estimando que la globalidad de los procesos que vivimos no permite ya evadirse "con la coartada de las culturas regionales, ni con las nostalgias historicistas"

Choay constata que "la historia de las formas urbanas, tan reveladora para comprender el pasado y tratar los antiguos tejidos urbanos, ha servido de aval al historicismo lúdico de técnicos aficionados y ha legitimado la defensa de modelos caducos (Leon y Robert Krier o Charles Moore)" ${ }^{10}$.

En tanto, Mc Leod condena las tendencias historicista y posestructuralista por haber abjurado de todos los campos de lo social, y por haber supuesto que la forma es una herramienta crítica y ratificatoria independiente de los procesos sociales y económicos, concluyendo que "los costes formales y sociales son demasiado altos cuando la atención se centra de un modo tan exclusivo en la forma"11.

una integración social, nacional, latinoamericana, los móviles del goce que hoy están presentes: la seducción del vértigo, la ligereza de vínculos, la aventura de los intersticios, la pasión individual, la exaltación de las formas y la consecuente pérdida de sustancialidad. pp.27-30.

8 SOLA-MORALES, Ignasi de, "Territorio construido: la ciudad desde la arquitectura", en Arquitectura Viva, No35, marzo-abril 1994, pp.31-37.

9 Ibid.

10 CHOAY, 1994, op. cit.

11 MC LEOD, Mary, "La era de Reagan, del posmoderno a la deconstrucción", en Arquitectura Viva, No8, Oct. 1989 , pp.7-19. 


\section{Urbanista de fin de siglo: un técnico, entre muchos}

El fenómeno de tecnificación, que ha transformado las prácticas del urbanismo, alejó al urbanista de su status tradicional para hacer de él un técnico entre muchos, y aun cuando su papel de creador espacial competente se ha reducido bastante en la práctica, permanece como imagen en ciertos medios y público en general.

Al tiempo que disminuye el lugar concedido al urbanista "no-técnico", ocupan su puesto oficinas de estudios para tratar técnicamente problemas de ordenamiento, conquistando sectores completos del transporte, las infraestructuras, el ambiente urbano, campos sobre los que el urbanista podría haber tenido ciertas pretensiones ${ }^{12}$. La víctima, en diversas partes del mundo, es el arquitecto-urbanista, y el vencedor, el técnico ${ }^{13}$.

Sin duda el habitar no se define sólo por la consumación de contrastes espectaculares de líneas, volúmenes y colores, tampoco lo esencial es la oferta de un ego a la posteridad.

Desde hace más de un siglo, observa Choay, el urbanismo tiene la pretensión de una aproximación global y científica, crítica y reflexiva de la ciudad ${ }^{14}$. Sin embargo, salvo raras excepciones, el pensamiento urbanístico llega a apropiarse -ni tampoco a articular- la visión reticular de los territorios que poco a poco se ha ido desarrollando.

"La dinámica de las redes ha tendido a sustituir a la estática de los lugares edificados, condicionando lugares y comportamientos urbanos. Un sistema de referencia físico y mental, constituido por redes materiales e inmateriales, así como por objetos técnicos -cuya manipulación pone en juego imágenes e informaciones-, resuena en un circuito que se cierra sobre las relaciones que mantienen nuestras sociedades con el espacio, el tiempo y las personas. Este sistema operativo, válido y factible en cualquier lugar, en las ciudades y en el campo, en los pueblos y en los suburbios, puede ser llamado "LO URBANO"15.

Hoy domina "lo urbano", que se despliega por los territorios a través de las redes de todo tipo; domina la "interactividad" sobre la "actividad" ("networked city") ${ }^{16}$; estamos

12 En Chile, en materia de transporte en general y de transporte metropolitano en especial, los arquitectos chilenos tuvieron una participación histórica al dar origen a oficinas, estudios y proyectos, hace casi cuarenta años: Vialidad Urbana, Metro de Santiago, encuestas de origen y destino, modelos de desarrollo urbano y de transporte, planes reguladores de transporte y otros, incluida la gestión para sus financiamientos, dirección, construcción y explotación. Sobre cien arquitectos fueron incorporados a la especialidad por el arquitecto y Urbanista Juan Parrochia Beguin desde su pionera acción profesional, quien además dicta el curso de Transporte en la F.A.U.-U.CH. desde los años 60, situándose desde 1985, en el Magister en Urbanismo.

13 DUPUY, Gabriel, Urbanismo y Técnica: Crónica de un matrimonio de conveniencia, Ed. OIKOS, Asociación para la Promoción de Estudios Territoriales y Ambientales, Buenos Aires, 1984, 299 págs. ilustradas, pp. 1820.

14 CHOAY, Françoise, L'Urbanisme, utopies et réalités. Une Anthologie, Éditions du Seuil, 1965.

15 CHOAY, 1994, op. cit.

16 TARR, J. et al, 1988; y TARR, J. et al, 1990, op.cit. 
frente al "despliegue de una excentricidad generalizada -periferia sin fin-signo anunciador de la superación de la forma urbana industrial"17.

El concepto de ciudad visto como parte de un binomio que opone ciudad y campo, dejó de ser válido hace tiempo. Las revoluciones mundiales del siglo XIX, están al origen de la conformación del "territorio ecuménico continuo", que es dinámico, combativo y expansionista, y donde lo urbano y lo rural sólo son una división metodológica de análisis de dudosa eficacia.

El concepto de "metrópoli" ya vislumbrado a principios del siglo $X X$, entendido como integración urbano-rural de grandes áreas polarizadas sobre uno o varios núcleos, es uno de los primeros anuncios de la nueva concepción territorial que, invirtiendo el proceso de concentración de la vida y de la actividad en la ciudad, encierra el retorno hacia el exterior inundando el territorio circundante. Aun cuando esto representa una nueva era de la civilización, pensadores, gobernantes y profesionales siguen operando como si nada ocurriera ${ }^{18}$. Parece llegado el momento en que el urbanismo se dé los medios intelectuales para entender la ciudad tal como ella es actualmente, y para pensar su futuro.

\section{Críticas a la manera dominante de pensar la ciudad, y también las redes}

Se critica al urbanismo su incapacidad para tomar en cuenta otros territorios diferentes de los "homomorfos a las zonas que tradicionalmente ha definido"19. Frente a la concepción territorial de la zonificación funcionalista, diversos especialistas contemporáneos proponen la reconsideración de la dimensión analítica asociada a la territorialidad "reticular", "trasgresora de zonas y límites".

No se trata de negar los tipos de territorialidad de áreas legítimas conocidas como la comuna y otras, ni los poderes que se ejercen en ellas, sino de asumir que el carácter masivo del desarrollo de las redes, el rol singular de las telecomunicaciones -cuyo esquema funcional particular reviste de significaciones nuevas a las "viejas" redes técnicas- ha engendrado realmente un nuevo tipo de territorialidad urbana, en vía de rápida difusión, que el urbanismo, en general, ha ignorado hasta ahora.

Es evidente que la habitación constituye con su entorno, una unidad con accesos, límites, fronteras, que no se intentará reducir a una territorialidad reticular. El barrio no ha desaparecido como territorio para todas las actividades y personas que lo habitan. En materia de poblaciones de interés social, el pequeño centro comercial y los lugares que lo rodean constituyen el solo espacio social, el único territorio más allá de

\footnotetext{
17 VIRILIO, Paul, "Cité, Miroir, agonie", en: Les Annales de la Recherche Urbaine, N034, juin-juil., 1987, citado por Dupuy, 1991, op.cit.

18 PARROCHIA B., Juan, Santiago en Chile. Evolución y Proyección Estructural de la Región, manuscrito inédito, 1981, 28 págs. Archivo de Juan Parrochia Beguin, 1999.

19 LACOUR, Claude, "De l'aménagement du territoire au développement du territoire: essai de théorisation sur une notion vague:le territoire", en Région et aménagement du territoire, mélanges offerts au Doyen Lajugie par ses collègues, ses élèves et ses amis, Bordeaux, Brière,1985, citado por Dupuy, 1991, op.cit.
} 
la vivienda, del cual los habitantes más pobres suelen ser verdaderos "cautivos" en razón de la baja movilidad que determina su escasez de recursos, entre otros ${ }^{20}$.

No obstante, las redes se han ido sumando a los nodos y áreas utilizados por los actores sociales, económicos y políticos, para generar territorialidades, las que se van combinando sutilmente en sistemas territoriales tan complejos como la ciudad misma. El ingeniero francés, Dr. Gabriel Dupuy quien ha presentado la primera aproximación sintética al urbanismo de redes, advierte:

"Las bases sobre las que se fundaba el Urbanismo se encuentran, si no socavadas, al menos sacudidas. Las nuevas tecnologías de comunicación significan, a lo menos, la muerte de cierto tipo de ciudad: aquella que los urbanistas han pretendido manejar en sus planes"121.

En gran parte del presente siglo el urbanismo institucional ha operado con la territorialidad de las "zonas", áreas que son delimitadas y afectadas a un determinado tipo de construcción, actividad, densidad, con mayor o menor detalle y logro de objetivos, según sean las bases jurídicas, históricas y culturales del país que se considere.

El conjunto de zonas, también delimitadas por un perímetro -límite urbano- constituye el "área urbana", que se distingue de otras áreas urbanas contiguas o de un espacio "rural". Esta es la territorialidad de la propiedad individual o colectiva, pública o privada, la territorialidad de límites y fronteras naturales o institucionales, desde donde se ejercen múltiples poderes pequeños o grandes ${ }^{22}$.

El instrumento por excelencia, el modo de concepción y de representación privilegiado por la urbanística reforzada y codificada por Le Corbusier y la Carta de Atenas, sigue siendo el plan regulador ("plano" director, de ocupación del suelo, de ordenamiento, de urbanismo) que es, al mismo tiempo, "un procedimiento reglamentario y la manera dominante de pensar la ciudad en términos urbanísticos"23.

Sin embargo, el plano regulador no gobierna los transportes, la electricidad, la iluminación, el gas, el agua, la recogida de basuras, el servicio de saneamiento, el teléfono, la televisión, el telemercado, los cajeros automáticos, la teleseguridad, la calefacción urbana, servicios que, junto al trabajo, van constituyendo la vida cotidiana en muchas áreas habitadas del mundo occidental desde hace tiempo.

Así, los urbanistas van llevando un razonamiento que no da cuenta de la medida del conjunto de cambios que están afectado dichos servicios y sus redes -una verdadera mutación urbana-, apreciada claramente en los países desarrollados, frente a la cual el urbanista no debería ignorar por más tiempo las redes como concepto ni como objeto,

DUPUY, 1991, op. cit., pp. 58-59.

DUPUY, 1991, op. cit., p.10.

DUPUY, 1991, op. cit. p.13

Ibid. p.65. 
no debería ignorar la calidad de "abonado a puntos nodales del espacio red", de los habitantes de la ciudad ${ }^{24}$.

"Desde hace más de un siglo, las redes de circulación, de energía y sobre todo de comunicación, han recompuesto una ciudad donde los nudos cuentan más que las zonas, las conexiones más que las fronteras, el tiempo tanto o más que el espacio. Esta nueva composición urbana orienta las prácticas cotidianas de los ciudadanos y da un sentido social global a la noción de red. ¿Cómo admitir que ella continúe siendo ignorada por la gestión urbana ${ }^{25}$

En cuanto a los responsables habituales de las redes, ingenieros y técnicos, ellos son denunciados por privilegiar -aún a fines del siglo XX- una concepción limitada y circulatoria de ellas ("máquinas para circular"), y, a pesar de que existen relaciones evidentes entre las diversas redes (el servicio de alcantarillado es estrechamente dependiente del servicio de agua; el transporte colectivo de las posibilidades energéticas, del estado de la red vial, del desarrollo del transporte individual, etc.) las redes se desarrollan en un marco sectorial ${ }^{26}$, que en nuestro contexto ve una incontenible privatización de los servicios, lo cual dificultará aún más la posibilidad de aplicar criterios integradores en las formaciones urbanas.

Ante todo problema de redes, los urbanistas tienen la tendencia de dirigirse a estos profesionales para su tratamiento, "sin captar toda la significación social, los alcances espaciales y el aspecto territorial estratégico de ellas"27. La significación social del fenómeno no radica solamente en el suministro técnico de un simple servicio local, sino en su rol constitutivo de una nueva territorialidad: la compleja territorialidad reticular. Se trata de una multitud de actores que se vuelven solidarios gracias a las redes técnicas, y "societarios" por su pertenencia a sistemas de gestión de las conexiones en la red. Las redes alcanzan, además, el espacio exterior al perímetro urbano tradicional, participando de nuevas implicaciones sociales y de nuevas territorialidades ${ }^{28}$.

\section{El movimiento como esencia de la urbanidad}

En la ciudad de la zonificación, la localización de actividades determina las "entidades" constitutivas de la ciudad, lógicamente anteriores, si no independientes de las relaciones que se establecen entre ellas, y que un sistema de transporte, entre otros, está encargado posteriormente de asegurar.

En esta concepción se desconoce que el movimiento de los hombres no es la consecuencia, sino la esencia de la urbanidad. Amar considera el movimiento como el hilo director de una aproximación ecológica de los asentamientos humanos que se interesa en las maneras según las cuales el ciudadano entra en contacto con sus

24 DE RADKOWSKI, Georges-Hubert "Le Crépuscule des sédentaires", en: L'Homme de la Ville, JANUS, 1967, citado por Dupuy, 1991, op.cit., p.66.

25 DUPUY, 1991, op. cit., p.66.

26 DUPUY, 1984, op. cit. Vid. cap. "Las técnicas de Vialidad y Redes Diversas", pp.59-60.

27 DUPUY, 1991, op. cit., p.40-41.

28 Ibid. p. 43, y p. 57. 
semejantes y con su entorno en sentido amplio: físico y sensible, pero también social, económico, cultural, es decir, en las modalidades efectivas de la habitación, la que no se reduce al "apartamento", sino que significa también habitar una ciudad, un país, una cultura, una naturaleza.

También se interesa en las modalidades efectivas de socialización, la que no se reduce a una pertenencia comunitaria o profesional, sino que incluye co-presencias y encuentros imprevistos en un amplio territorio, idealmente sin barreras ${ }^{29}$, donde la pertenencia a comunidades de intereses diversos ya no se funda en la proximidad o en la densidad demográfica local. Arraigo y pertenencia son nociones que han perdido parte, si no todo su sentido, y que deben ser repensadas en función de nuevos parámetros y según una relación inédita con la temporalidad ${ }^{30}$.

Así, el movimiento en el caso de las redes de transporte, por ejemplo, no se asocia a un medio neutro (movimiento en el "no-lugar" y "tiempo perdido") para ligar dos lugares ya conocidos y "funcionalizados" (domicilio-trabajo, etc.), sino que actúa como un "generador" participando y animando múltiples actividades y espacios: el movimiento es operador y modo de urbanidad a la vez.

Y, lo que distingue los tipos de movimientos es su grado y modo de "adherencia al tejido/medio urbano": la marcha a pié en un extremo, muy "próxima" a la ciudad; el viaje en avión en el otro extremo, muy "lejos" de la ciudad. Entre ellos, la bicicleta, el automóvil, el autobús, el tranvía, el Metro (que en todo el mundo busca esa mayor "adherencia" creando puntas intermedias entre las extremas domicilio-trabajo, asociadas a otras actividades y lugares), y el ferrocarril.

Todos los tipos de movimiento en materia de transporte en este caso, ofreciendo un continuum que va desde las más altas a las más bajas adherencias, y a los que corresponden formas específicas de accesibilidad urbana, cualidad urbana, tal vez por excelencia: la "ciudad accesible" no sólo como un ideal hoy, sino como la idea misma de ciudad ${ }^{31}$.

"El desafío del devenir urbano del movimiento, está a la vez en la diversificación de los tipos de movimientos y en la articulación de los modos de transporte que los producen; porque es éste doble dinamismo el que permite integrar el transporte a la ciudad poniéndola en movimiento. Es una "dinámica de redes", que atraviesa el conjunto de los sistemas de trasporte, en el cual cada uno opera en una región del espacio de las movilidades. Esta "dinámica de redes", desde el momento que tiene por objetivo la continuidad, no sólo entre los diversos tipos de movimientos, sino entre movimientos y actividades fijas, no es otra cosa que la dinámica de la ciudad misma"132.

\footnotetext{
29 AMAR, Georges, "Pour une écologie urbaine des transports", en: Les Annales de la Recherche Urbaine: Mobilité, N059-60, Juin-Septembre 1993, Paris, p. p. 140-151.

30 CHOAY, Françoise, 1994, op.cit.

31 AMAR, G., 1993, op. cit.

32 Ibid.
} 


\section{La accesibilidad a las redes: un objetivo cívico}

Un conjunto de relaciones permitidas, pero también escogidas en el tiempo y en el espacio en virtud de redes de todo tipo, convertirían los asentamientos humanos en espacios de mayor libertad para el desarrollo pleno del individuo y la sociedad.

Frente a este ideal, la accesibilidad a las redes de todo tipo como objetivo cívico, es un concepto relevante que debe ser esclarecido dada la ambigüedad con que suelen ser tratadas, por ejemplo, la movilidad cotidiana y residencial en el espacio: como un derecho (acercamiento del domicilio al trabajo), pero también como una restricción (enraizamiento residencial como condición de la sociabilidad urbana).

Por otra parte, tal como el desplazamiento va contra la cultura de la sedentarización, la civilidad va contra la exclusividad territorial. Esta última oposición exige a la sociedad civil que sus miembros aprendan a coexistir con individuos diferentes, especialmente en espacios públicos. La coexistencia es condición de la accesibilidad ${ }^{33}$.

El aprendizaje del desplazamiento que posibilita la sociedad civil, implica la difusión y enseñanza de los códigos de multi-territorialidad y de las reglas de desenvolvimiento en todos los lugares. Por cierto que esta capacidad, está desigualmente distribuida hoy en la población.

En nuestro contexto, toda vez que los "excluidos" operan fuera del marco de la ley, incrementan el volumen de la delincuencia, frente a lo cual las viviendas van adoptando aspecto de fortaleza (despliegue del condominio, feudalización de la ciudad), y los espacios públicos, aspecto despoblado, o policíaco. Pero, se nos recomienda no ser tan apocalípticos al observar estos problemas, aunque también no creer demasiado en la utopía de la integración: nunca antes hubo mayor concurrencia de opciones de integración -revolución de las comunicaciones, ampliación de los mercados, interconexión global, intercambio cultural-, y tan alto grado de desintegración ${ }^{34}$.

En una América Latina donde, en volumen absoluto, hay más pobres hoy, que hace una década, y la distribución del ingreso es menos equitativa que a principios de los ochenta, sin duda la vida cotidiana no es igual para todos ${ }^{35}$. Los ciudadanos con mayor grado de integración, despliegan su vida cotidiana por un territorio generalmente mayor que la "zona" y comuna donde viven, pues sus empleos no se sitúan necesariamente en estas, tampoco los establecimientos educacionales donde asisten sus hijos, ni el comercio donde compra la familia.

Se trata de desplazamientos cotidianos que ya no se explican por la teoría de las necesidades en sentido estricto, pues dependen, entre otros, de los objetivos que se fijan los individuos (prestigio, distinción, enmarcado social, etc.), y cuyo punto de

\footnotetext{
33 HAUMONT, Antoine, "La Mobilité intra-urbaine:rétrospective et prospective", en Les Annales de la Recherche Urbaine: Mobilité, N059-60, Juin-Septembre 1993, Paris, pp. 108-117.

34 HOPENHAYN, 1994, op. cit., p. 61.

35 Ibid.
} 
partida central es la residencia, desde la cual los miembros de un hogar definen su propia ciudad en relación a una multitud de destinaciones que pueden alcanzarse en forma creciente en automóvil ${ }^{36}$.

Estas categorías sociales tienen mayor experiencia en el uso estratégico de los desplazamientos y en su desenvolvimiento en contextos variados. Para ellos, la dimensión cotidiana de la vida supone hoy una diversidad creciente del consumo y una rápida incorporación de las ventajas del avance tecnológico. La informática y la telecomunicación hacen posible su conexión permanente con el mundo, tienen acceso ilimitado a la información y a intercambios a distancia de todo tipo y con todo tipo de pares.

En tanto, fracciones importantes de la población están aún sub-comprometidas con la movilidad cotidiana, porque ellas participan mal o no participan en los mercados regionales de empleo, consumen pocos bienes y servicios, y porque su vida cotidiana tiene lugar en un área limitada, donde la "cotidianidad del barrio", especie de receptáculo natural de las expectativas de esta masa de población, "libera" de alguna forma al individuo desarrollando una cultura de supervivencia a partir de la solidaridad entre vecinos ${ }^{37}$. Frente a esta realidad, se nos advierte:

"Sociedades tan inequitativas como las nuestras pueden tecnificarse; pero mientras permanezcan con tan altos niveles de exclusión, uno de los campos más fértiles de tecnificación será el manejo cada vez más modernizado de la pobreza para responder tanto al afán de lucro de los dueños de la técnica, como a la racionalidad instrumental de sus operadores" ${ }^{\prime 38}$.

Entre las múltiples facetas de este tema, cabe preguntarse en qué medida es factible aplicar en nuestros contextos las recomendaciones internacionales en el sentido de administrar las redes de infraestructura como una empresa comercial (privatización de la infraestructura y los servicios urbanos) toda vez que estas se dirigen a la demanda solvente, cuando la mayoría de la población se encuentra en situación de pobreza y la mayor parte de nuestras ciudades son construidas informalmente.

Si los gobiernos tienen la responsabilidad de defender los intereses de los sectores pobres -lo cual se presenta como secundario en las recomendaciones- ¿debería entonces ser propuesto un verdadero "derecho a las redes para todos", con un "acceso mínimo local" para cada habitante? ${ }^{39}$

\footnotetext{
36 FISHMAN R.," The Post-War American Suburb: a New Form,a New City", en: SCHAFFER D. (Ed.), Two Centuries of American Planning,Londres, Mansell,1988, citado por Dupuy, 1991, op. cit.- En los E.E.U.U. todo lo que requieren los habitantes puede encontrarse junto a las autopistas. Así, los centros de ciudad han casi desaparecido en los hechos de su experiencia cotidiana, el centro está hoy en todas partes. No se trata aquí, advierte G. Dupuy, de una suburbanización -"dependencia distante, pero fuerte, entre periferia y centro"-, sino de otra cosa, "aquello que ya anunciaba el proyecto ["profético más que utópico"] Broadacre de Wright".

37 HOPENHAYN, op. cit. , pp.23 y 46.

38 Ibid., pp. 41-42.

39 En los E.E.U.U. grupos de reivindicación han exigido y obtenido que la legislación prevea un acceso mínimo local para todos a las redes telefónicas, (Dupuy, 1991, op. cit. p. 47). En Alemania se considera un
} 
La expansión tecnológica, y con ella un mayor grado de desarrollo, podrán llegar de alguna forma a la población más pobre, siempre que una integración social de las sociedades sudamericanas lo hagan viable ${ }^{40}$.

$\mathrm{Y}$, en cuanto a un urbanismo técnico hecho por técnicos, (ingenieros en general) es difícil que los habitantes puedan participar en este tipo de experiencias, en los hechos, en gran medida están excluidos de ellas. En nuestro contexto, podemos citar el caso de la implementación de proyectos de vialidad del sector privado, para su manejo en concesión -por ejemplo la variante de la Ruta 78, sector Malloco a General Velásquez, sin coordinación incluso con el Plan Metropolitano de Santiago, y diversos Planes Reguladores Comunales afectados por su paso. En el caso de estos últimos instrumentos, el reemplazo de los principios que han guiado la acción urbanística, por la expresión de la voluntad de los habitantes -a priori interesados por la producción de la administración de su marco de vida- se reduce en la práctica a una negociación entre poder público y poder de algunos privados sobre los derechos de uso del suelo.

\section{Legitimidad del urbanismo en el campo de las redes}

Los pensadores del urbanismo de las redes no desconocen el problema del suelo, y por ello no rechazan el urbanismo actual, ni lo reducen, sino que lo refuerzan, intentando hacerlo más eficaz al servicio de la comunidad incorporando un nuevo plano o dimensión analítica: el de la redística.

"Es con el conjunto de todos los operadores de redes diversas, cerca de ellos, comprendiendo sus lógicas, también sus dificultades, y, sobre todo, sus límites, y no contra ellos, o lejos de ellos, que el urbanismo debe encontrar su nueva definición" ${ }^{\prime 1}$.

Pero para ello se indica que sería indispensable comprender la nueva significación de las redes en tanto organización de la relación de la sociedad con sus territorios, y, en la base de la noción de red, la afirmación de una diversidad, de una heterogeneidad fundamental en el tiempo y en el espacio ${ }^{42}$.

También es necesario admitir la noción de proyecto "transaccional", a partir de una voluntad que busca relacionarse, asegurar las funciones, influenciar, controlarse, prohibirse, permitirse, alejarse, acercarse ("líneas de deseo", en transporte urbano; "matrices de afinidad", para teléfonos, etc.). El espacio es transformado en territorio por la intencionalidad del actor.

subsidio a las personas desfavorecidas, para su acceso al transporte colectivo (BORCHARD, Klaus, Conferencia: Vialidad Urbana en Alemania, F.A.U., Universidad de Chile, Marzo 31, 1995).

40 HOPENHAYN, op. cit.

41 DUPUY, 1991, op. cit., p.182.

42 Ibid., p. 108. 
El urbanismo se convierte en la única posibilidad colectiva de realización de proyectos individuales de esta naturaleza; será raro que el poder de un solo actor lo logre. En general es el actor colectivo el que puede concretizar el proyecto "transaccional" gracias a una especie de delegación colectiva de poderes en un "operador". Pero, mientras el operador público hace prevalecer una lógica de política urbana o rural, el operador de la empresa privada privilegia la lógica económica, para lo cual constreñirá al máximo la red "transaccional", la que, habida cuenta de sus características de imaginariedad y virtualidad, tiende teóricamente a ser una red máxima ${ }^{43}$.

Es necesario además, que la organización en redes -en sus diversos niveles de operación- se coordine, se componga con esas territorialidades que el urbanismo reconoce desde hace mucho tiempo. Dichos niveles de operación implican operadores de primer nivel (redes ruteras, redes de transporte en común, redes telefónicas, etc.); operadores de segundo nivel (redes de producción, redes de consumo, que corresponden a ciertas formas clásicas de intervención en urbanismo), y operadores de tercer nivel (el hogar urbano construyendo su propia estructura de red).

El urbanismo tiene una legitimidad histórica en el campo de las redes, porque verdaderos urbanistas han otorgado a las redes un lugar principal en su concepción de la ciudad desde el nacimiento del pensamiento urbanístico hasta ahora. El rol del urbanista junto a los operadores es posible y necesario en todos los lugares donde se realizan redes reales: para favorecer la consideración de redes virtuales, para facilitar las articulaciones con los otros niveles de operadores, para mejorar la consideración global de las redes técnicas cada vez que esto pueda tener ventajas para la colectividad, en fin, la legitimidad es social también porque la realización de las redes que de hecho organizan la ciudad moderna-, llama a una intervención al servicio de la colectividad para regular y controlar los operadores, pues ellos no están ajenos a la perversión política, económica o técnica ${ }^{44}$.

\section{Organización territorial en red}

Aun cuando las redes tengan, o pudieran tener una existencia física, la percepción de ellas no es evidente. Existen vías desde milenios, pero la noción de red rutera emergió recién en el siglo XVIII, de igual forma respecto de las alcantarillas, su concepción como red de saneamiento es un concepto de fines del siglo pasado ${ }^{45}$. En cuanto a la idea de la organización territorial urbana en red, se constata que existió en el pasado pero absolutamente marginada.

Ildefonso Cerdá, Franck Lloyd Wright y Maurice F. Rouge, entre otros, han sido estudiados por el Ing. Gabriel Dupuy -a partir de la noción contemporánea de redpara enriquecer una nueva aproximación a la ciudad actual. Ellos hicieron aproximaciones globales al conjunto de las redes técnicas disponibles en sus épocas,

\footnotetext{
43 Ibid., p.110.

44 Ibid., p. 123.

45 DUPUY,Gabriel, Systèmes, Réseaux et Territoires: Principes de Réseautique Territoriale, Presses de L'Ecole Nationale des Ponts et Chaussées, 168 págs. , París, 1985.
} 
en sus relaciones con el espacio urbano (por oposición a otras sectoriales: transporte, etc.).

Cerdá, tiene en su Teoría General de la Urbanización, largos pasajes sobre las redes. Wright, en Broadacre, genera una "utopía absolutamente urbana" donde la dispersión es posible porque solidariza al mismo tiempo gracias a las redes.

Wright no sugirió volver a las comunidades naturales, que estimaba superadas. La concentración urbana, cuando ya existía el teléfono, la electricidad, el automóvil, no tenía sentido.

Rouge tiene una visión muy perspicaz de la relación ciudad-redes. Otto Wagner, autor, en 1893, de un proyecto de ordenamiento fundado sobre una topología contemporánea de red, se opone al urbanismo "clásico", no repartiendo a priori los elementos de la ciudad sobre el espacio geográfico. Industrias, residencias, oficinas, y otros, se dispondrían sobre las redes, sin referencia a zonificaciones ${ }^{46}$.

Los especialistas en redes advierten hoy que la red no debe ser apreciada como consecuencia de una innovación tecnológica, sino como un principio de ordenamiento que relaciona posibilidades técnicas y el servicio de un territorio. El ordenamiento de los territorios se realiza también por el establecimiento de redes que lo sirven, que lo irrigan, que lo informan y que lo organizan.

La experiencia muestra, además, que hay una relación entre evolución de los territorios y evolución de las redes ${ }^{47}$. En efecto, los problemas de redes de infraestructura por ejemplo, en países en vías de desarrollo, restringen seriamente la productividad de muchas ciudades, al no poder atraerse la inversión privada y al poner en peligro la salud pública y la seguridad de la población.

Se considera que una red de infraestructura adecuada reduce los costos de producción, los cuales afectan la rentabilidad, los niveles de rendimiento y empleo, particularmente en los negocios de pequeña escala. Cuando ella no funciona, la dinámica puede disminuir e incluso detenerse. Por cierto que la falta de mantenimiento de los servicios, también tiene su costo.

Sin duda la infraestructura influye en las dimensiones de la pobreza, y se piensa que la prueba de eficiencia en el manejo de las ciudades es el estado de provisión de las redes de infraestructura ${ }^{48} 47$. Toda vez que las áreas urbanas tienen adecuados servicios de infraestructura -la infraestructura como una especie de fideicomiso público- se contribuye a la cohesión y desarrollo de la comunidad; su renovación es también la de la cultura de un país y de su sistema de valores, aportando tanto como la creación de centros culturales, museos y monumentos ${ }^{49}$.

\footnotetext{
46 DUPUY, 1991, op.cit.

47 DUPUY, 1985, op.cit.

48 MABOGUNGE, Akin, "La infraestructura: la clave del desarrollo moderno", en La Era Urbana, Ed. Banco Mundial, primavera 1993, p.3.

49 Ibid.
} 
A pesar de lo señalado, quienes intervienen en el ordenamiento, la concepción, la gestión de la redes, no son conscientes realmente de los lazos esenciales que se establecen entre la red y el territorio ${ }^{50}$. Para analizar convenientemente su complejidad, un nuevo esfuerzo teórico es requerido:

"Es necesario superar la visión tecnicista y, en consecuencia, sectorial -relativa a cada red- que muy a menudo especifica totalmente la red en función de los fenómenos físicos que ocurren en ella. También es necesario superar la noción geográfica clásica del territorio que se refiere a su descripción monográfica" ${ }^{51}$.

\section{Aproximación sistémica y función relacional de las redes}

La aproximación sistémica -evolutiva y adaptativa- de los territorios, sea que se trate de una ciudad, una región, de una nación, o de territorios más vastos, permite una lectura diferente del espacio no sólo geográfico, sino también socio-económico. Las redes, cualesquiera que ellas sean, encuentran su lugar en esta aproximación, sus características técnicas no aparecen sino después ${ }^{52}$.

Las redes públicas clásicas conocidas representan inversiones colosales cuya duración de vida y de amortización es de varias decenas de años. De allí el interés de poder analizar adecuadamente los procesos de adaptación sistema territorial-redes. Se trata de transformaciones de largos períodos que requieren un análisis diacrónico para el cual los conceptos y métodos corrientes de análisis de redes no son pertinentes.

La ingeniería trabaja con una aproximación sincrónica, haciendo funcionar convenientemente la red en un momento determinado, sin mayor consideración al hecho que la red deberá operar mutaciones como consecuencia de las mutaciones del sistema territorial (la dimensión adaptativa es una característica mayor de la red).

La teoría general de sistemas ha sido concebida para estudiar procesos, trayectorias, evoluciones, el tiempo juega aquí un rol esencial. Dado que una red se sitúa en relación a la realidad de un territorio que es multifacética y que debe ser representada en toda su riqueza y variedad, se estima que es en la perspectiva de la representación sistémica global que debe situarse el estudio de las redes, aún si en la práctica debamos conformarnos con representaciones parciales ${ }^{53}$.

Sin embargo, primero deben superarse algunos problemas. La representación sistémica, conforme a la teoría general de sistemas, se acomoda mal a la localización de actividades humanas en el espacio físico. Años de planificación y ordenamiento espacial con la ayuda de planos y cartas han habituado a una percepción euclidiana.

\footnotetext{
50 DUPUY, Gabriel, "Systèmes, réseaux et territoires", Primer curso sobre sistemas, redes y territorio, dictado en el Instituto de Urbanismo de París, Nivel D.E.A., Universidad de París XII, año académico 198485.

51 DUPUY, 1985, op. cit.

52 Ibid.

53 Ibid.
} 
En el plano regulador de una ciudad, las redes se diseñan en un espacio de dos dimensiones. Las distancias están a escala y dan la representación casi física de la red. En la representación sistémica no hay espacio continuo de dos o tres dimensiones, lo que cuenta es la conciliación de los sub-sistemas, sus lazos, sus aperturas al entorno. Si se busca localizar partes del sistema, se deberá hacer en espacios abstractos, espacios de $n$ dimensiones, inhabituales para el urbanista, y que no corresponden a la percepción inmediata de las redes "clásicas".

La representación liberada del espacio físico presenta ventajas, pues en materia de redes importa menos el tema de las distancias que el de otras propiedades de los sistemas. Se abre paso así, a una concepción relacional de las redes, desestimando el postulado que el espacio determina las redes, pero admitiendo que ellas pueden también producir espacio. Se trata de lograr mucho menos un plan de zonificación, que "mecanismos de regulación o de manejo de los sistemas conforme a una política urbana"54. La visión de un espacio como sistema territorial permitiría así comprender mejor el lugar esencial, el rol estratégico de las redes, desde el momento que las abstrae de su materialidad para definirlas por su función relacional. Ciertas propiedades de las redes, la conexidad, la nodalidad, se vuelven particularmente pertinentes, pues globalmente fundan el carácter sistémico del territorio.

\section{La naturaleza del desafío al Urbanismo}

Como producto de los avances tecnológicos se ha llegado hoy a la abolición del tiempo para establecer la comunicación, a la anulación del sentido de la distancia física. Si la percepción del tiempo influencia directamente la concepción del espacio $y$, en consecuencia, orienta la organización, se estima que debería producirse entonces una transformación profunda en la manera de concebir el espacio-tiempo, lo cual debería traducirse territorialmente ${ }^{55}$.

En ausencia de la comprensión del hecho urbano en su nueva realidad, de un pensamiento urbanístico contemporáneo, de una definición teórica del lugar del urbanismo práctico, se encuentra, sin duda, grandes dificultades para definir una adecuada formación profesional y para lograr el reconocimiento a la disciplina, especialmente cuando la progresiva disminución de la participación del Estado está en curso dejando un claro vacío en beneficio de los actores privados -que operan en la perspectiva de un cortoplacismo exacerbado- $y$, en un contexto de descentralización, en beneficio de las colectividades locales, las que no cuentan con los conocimientos y experiencia suficientes para tomar decisiones en materia de ordenamiento territorial integral.

Se nos señala, como una de las tareas impostergables de los urbanistas, sacar el pensamiento urbanístico reticular de su marginalidad, fundar mejor la noción territorial de red, favorecer en el debate urbanístico moderno una discusión sobre la

\footnotetext{
54 DUPUY, 1985, op.cit.

55 "La Citta: Dallo spazio storico allo spazio telematico", en Convegno Internazionale, Bologne, Febrero, 1989, citado por Dupuy, 1991, op. cit., pp.22-23.
} 
http://revistaurbanismo.uchile.cl

territorialidad, presentar, explicar, desarrollar los útiles que permitan la consideración de la "redística" dentro de la "urbanística"56. También la necesidad de asumir la transdisciplinariedad del Urbanismo, abandonando la compartimentación, para reflexionar en conjunto en la búsqueda de síntesis originales. Creemos que es el momento oportuno para preguntarnos también sobre los programas de desarrollo de nuestra enseñanza del Urbanismo, y su nivel de incidencia en la actualización de la formación profesional desde el pre-grado y hasta el pos-título y post-grado, especialmente cuando no parece deseable que la formación responda sólo a los requerimientos profesionales de corto plazo de la "ciudad-mercado".

Nota: Extracto de escrito publicado in extenso en revista De Arquitectura, N7, F.A.U. Universidad de Chile, 1996, pp. 10-13, ilustrado.

56 DUPUY, 1991, op.cit., p.23. 